$$
\text { INEEL/CON--97-00286 }
$$

\title{
DEVELOPMENT OF THE ENVIRONMENTAL MANAGEMENT INTEGRATED BASELINE AT THE IDAHO NATIONAL ENGINEERING LABORATORY USING SYSTEMS ENGINEERING
}

\author{
James A. Murphy, Robert M. Caliva and James R. Wixson \\ Lockheed Martin Idaho Technologies CopāôE IV DD \\ Systems Engineering Directorate \\ P. O. Box 1625 , MS 3750 \\ Idaho Falls, ID 83415-3750

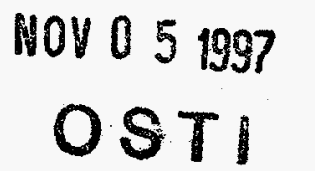

\begin{abstract}
The Idaho National Engineering Laboratory (INEL) is one of many Department of Energy (DOE) national laboratories that has been performing environmental cleanup and stabilization, which was accelerated upon the end of the cold war. In fact, the INEL currently receives two-thirds of its scope to perform these functions. However, the cleanup is a highly interactive system that creates an opportunity for systems engineering methodology to be employed. At the INEL, a group called EM (Environmental Management) Integration has been given this charter along with a small core of systems engineers. This paper will discuss the progress to date of converting the INEL legacy system into one that uses the systems engineering discipline as the method to ensure that external requirements are met.
\end{abstract}

\section{INTRODUCTION}

Similar to all other Department of Energy (DOE) sites, the Idaho National Engineering Laboratory (INEL) has been facing shrinking federal budgets at the same time local stakeholders are calling for greater regulatory accountability. Because approximately twothirds of all current funding at the INEL comes from the DOE-Environmental Management (EM) office, an effort was undertaken to create an INEL integrated baseline that would account for all the EM wastes and material streams in a costeffective manner. During the initial effort, a team was commissioned and generated a high-level baseline, which meant derived requirements at the lower level were not yet identified (Frandsen et al, 1995).

This paper will discuss the systems engineering approach used to identify these derived requirements for each waste stream, as well as the steps to be taken to validate the INEL's ability to comply with them. The process utilized involves several steps and phases, to include factfinding, validation, implementation and change control.

\section{PROBLEM STATEMENT}

EM Integration program requirements are not consistently traceable from the point of origin to the point of implementation, which indicates requirements derived for the individual work elements are not consistently traceable back to the external or top-level internal requirements. Even in those cases where the derived requirements are referenced to the external requirements, the interpretation and assumption logic involved in the derivation is often based on expert knowledge and is not necessarily complete nor recorded in the documentation. This often results in improper allocation of requirements from the top-down; a lack of traceability and accountability; and a baseline that is not defensible. Often the strategic, tactical, implementation, and work plans are out of synch with one another because of the development cycle of these static-natured planning and operational documents.

The use of static-natured documents, the nature of their development cycle, and the lack of dynamic connectivity with actual work plans results in considerable lag time before changes are made to affected work plans. As changes are made to requirements, interpretations, and assumptions; the changes also must be made to derived requirements and work plans. Stakes for failure to comply with external requirements, to include fines and penalties, are higher now because of the regulatory agreements which are in place.

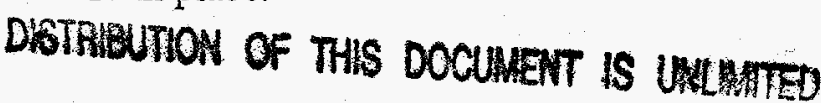




\section{MISSION AND GOALS}

\section{Mission}

Our mission (the work described in this paper) is to facilitate the development of the EM Integration program requirements baseline to ensure traceability from the point of origin to the point of implementation. Establishing the EM Integration program requirements baseline with this traceability will also serve to improve the purpose of independent reviews ("murder boards") as well as provide a mechanism to create a dynamic link between the elements of planning and implementation.

\section{Goals}

To accomplish this mission, we must ensure the final EM waste stream products meet clearly defined requirements and:

- work is traceable to the originating requirements

- related interpretations and assumptions are captured and maintained with the requirements

- potential for process improvement is maximized

- problems meeting extemal requirements are identified early on so that corrective action can be initiated and risk of failure can be better managed

- scope of work or funding changes can be evaluated in terms of a requirements trade-off

- the need for external assessments is reduced as a result of establishing a traceable requirements pathway along with the interpretations, assumptions, and resulting performance measures

\section{INEL EM REQUIREMENTS}

Within the INEL EM programs, there are many types of requirements. The two broad categories of requirements are the "what" and "how" requirements. The "what" requirements define scoping requirements for a function and generally define why a function exists. The "how" requirements are the procedural and safety related requirements that describe how a function might or must perform its work. It's important to note that both types of requirements can come from the same source document. The "how" requirements are typically entered into a matrix which links the requirements (INEL uses DOE order documents, CFRs, other laws or agreements) and the implementing procedure. Maintenance of each procedure is typically assigned to an organization that uses it. For the INEL EM program, there are thousands of these type of requirements, but they ARE NOT the focus of this effort.

The "what" requirements that are identified as scoping requirements define the purpose of a function to exist. However, even these "what" requirements can be segregated into two groups. The first group includes scoping requirements that have a time element in them. These can include regulatory milestones, agreements between governmental agencies, or commitments with DOE (eg State of Idaho Settlement Agreement, 1995). We refer to these in the paper as time-based scoping requirements. The second group are scoping requirements that say that something will be done, but a firm time for completion is not defined. These may come from strategic objectives from DOE or other stakeholders. These requirements clearly define why the INEL performs the work it does from year to year and are the focus of the remainder of this paper.

\section{Facts of Life at the INEL}

Critical to requirements development is the fact that the INEL maintains a legacy system which has been operational up to $40+$ years without a requirements management system. A typical waste stream may have a strategic element with a corresponding plan, which may or may not be implemented with a tactical plan, which may or may not have an implementation plan. Annual work plans are also developed that may or may not be orchestrated by the implementation plan.

Even if a program has all four elements, it is nearly impossible for all the elements to be in agreement with one another because of the time lag created in making four independently developed documents that are not required to be traceable. As mentioned earlier, with the climate of ever-changing (reducing) budgets, the programs constantly have to change what they do, which in itself, causes these documents to be out of synch.

However, one must understand that the INEL EM programs which systems engineering is attempting to develop a requirements management system for, believe they have already performed this action via the development of their planning and operational 


\section{DISCLAIMER}

This report was prepared as an account of work sponsored by an agency of the United States Government. Neither the United States Government nor any agency thereof, nor any of their employees, makes any warranty, express or implied, or assumes any legal liability or responsibility for the accuracy, completeness, or usefulness of any information, apparatus, product, or process disclosed, or represents that its use would not infringe privately owned rights. Reference herein to any specific commercial product, process, or service by trade name, trademark, manufacturer, or otherwise does not necessarily constitute or imply its endorsement, recommendation, or favoring by the United States Government or any agency thereof. The views and opinions of authors expressed herein do not necessarily state or reflect those of the United States Government or any agency thereof. 


\section{DISCLAIMER}

Portions of this document may be illegible electronic image products. Images are produced from the best available original document. 
documents. In fact, these documents have been successful in getting the programs adequate funding to do their work in the past. In many cases, the programs do not believe they need this extra systems engineering work as it adds a drain on their funding. Understanding this element helped to define another parameter; perform the requirements baseline development without costing much and with limited intrusion on the program experts' time. Without being in the middle of the process, it is hard to give the reader an appropriate appreciation for the sensitivity of this issue, but it is far from trivial.

\section{Aligning Strategic, Tactical, Implementation, and Work Plans}

The requirements baseline development process is attempting to take the elements of planning and implementation and align them dynamically in a requirements management system. This system must enable each element to work from the most current information available in terms of requirements, interpretations, and assumptions, as well as look at the actual performance of the functions against the planned performance. To create this dynamic system, the knowledge in the program experts' minds, as well as the program documents had to be gleaned and organized. To avoid the possibility of re-doing work already performed by these program experts, our process utilizes an interviewing process to ensure the data gathered from both documents and grey matter are the most current information describing each program.

A model or computer simulation is needed whenever the system is complex or when many variables exist. This can be used to generate and evaluate the internal requirements and the associated interpretations and assumptions necessary to comply with the external requirements. For the INEL, these are generally process models and are used as analytical tools with the EM waste streams to identify internal (derived) requirements that can be accomplished by the program functions to meet the overall external waste stream requirements. We have found that anytime there are many interactions between functions (greater than 3-5) or more than 3-4 variables, a model has been of great help in defining the internal functional requirements. Of the three programs so far, all required process models to derive the requirements set.

\section{Lessons Learned}

Interpretations and assumptions at each level of the requirements tree generate internal or derived requirements at the next lower level. These derived requirements often require their own interpretations and assumptions. Interpretations provide clarification of terms or further explanation of intent for a requirement. Assumptions are statements of belief about the magnitude, intention, condition, duration, etc. of a requirement. It is important to note that the levels within a requirements tree do not necessarily correlate or equate with the levels in a functional analysis. In other words, derived requirements can be broken down in greater levels of detail and yet still apply to the level 1 or 2 functional analysis. A picture depiction is given in Figure 1.

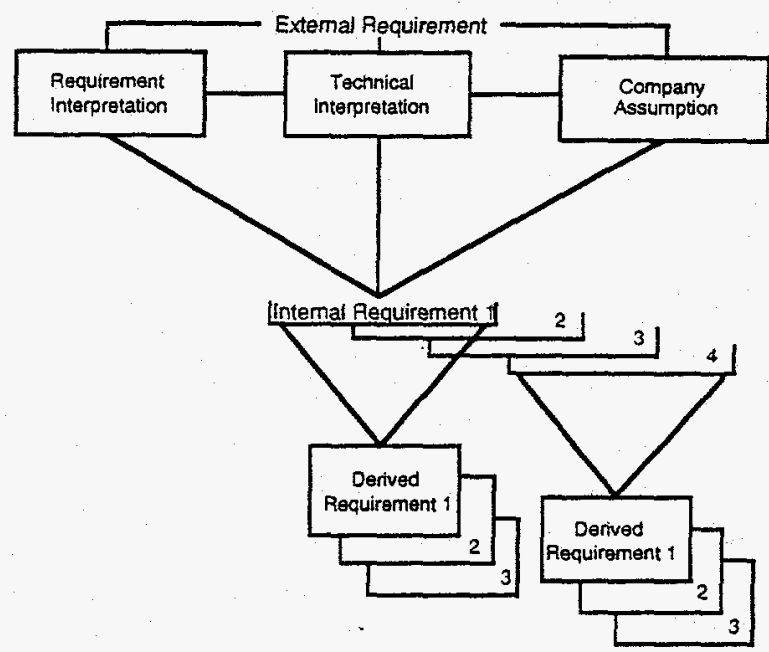

Figure 1, Elements of Requirements Flowdown

\section{Database Development}

To assist in organizing and managing the requirements, interpretations and assumptions, as well as relating them to the work breakdown structure (WBS) and organizational breakdown structure (OBS), a very specific requirements management system is being used. SLATE or System Level Automation Tool for Engineers, a software tool developed by TD Technologies, Inc. was recently purchased and is expected to facilitate 1) dynamic requirements management, 2) automatic documentation and report generation, 3) process modeling, 4) configuration management and data control, and 5) viewing of the current requirements 
data by anyone with work station access. Figure 2 (requirements to WBS relationship) illustrates the relationship between the requirements hierarchy and the company
WBS as it will be defined in SLATE. Key to the success of this effort will be completion and use of the requirements baseline database by the various EM programs.
INEL External
Requirements

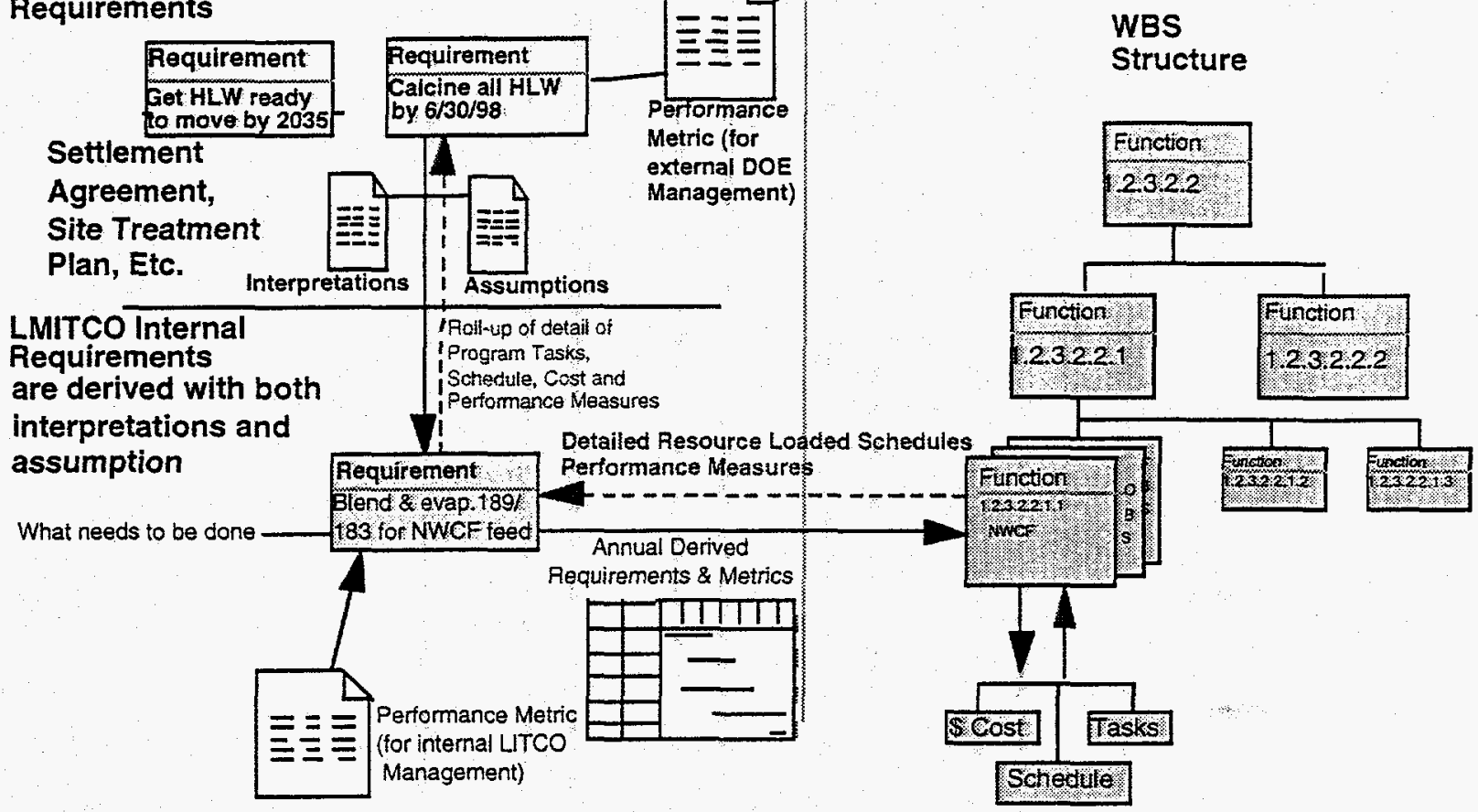

Figure 2, Requirements and Work Breakdown Structure Relationship

\section{PROCESS DESCRIPTION}

The process being used to develop the requirements management system is a multiple step, time-phased effort. The steps are performed for each waste stream during phase one, but only concentrate on developing the requirements data through the second level operation-based functional analysis. Functional analysis at level 3 or below, or any analyses of support or infrastructure activities are reserved for phase 2. The steps that are performed include factfinding, completion of missing data, validation of the requirements data set, and finally, implementation and change control. A figure of the process, along with the waste streams included in the INEL EM programs, is shown at Figure 3.

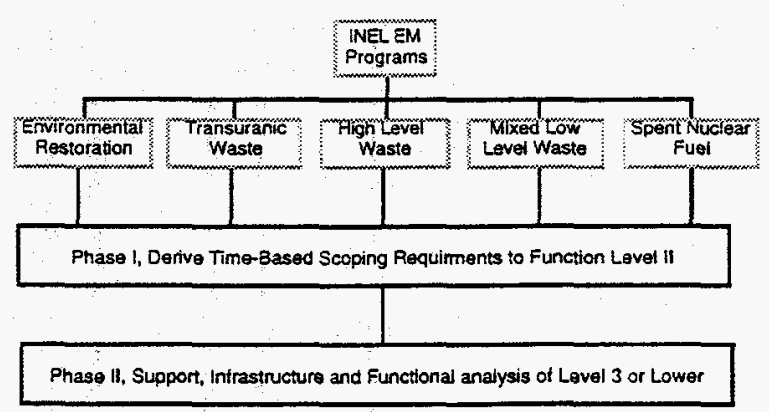

Figure 3, EM Integration Process and Program Involvement

\section{Factfinding}

The factfinding effort involves working with the subject matter experts within a program to identify the time-based scoping requirements. This includes researching any program documents for applicable information whether for internal requirements, 
assumptions, interpretations, or functional information. An attempt is made to capture these requirements down to level 2 via a functional analysis. Currently, approximately $50 \%$ of the waste stream requirements have been identified to this level. Level 1 and 2 functional and requirements analyses were initiated for the spent nuclear fuel (SNF) and high level waste (HLW) program areas. Finalization of their requirements data sets are being completed by systems engineers matrixed to them from the Systems Engineering Directorate, who are pursuing a course of action consistent with that started by the EM Integration effort.

In the Transuranic (TRU) Waste program (which is responsible for the disposition of transuranic waste), the systems engineering team, in concert with subject matter experts, have developed a functional analysis down to level 2 that is being used to facilitate the identification of derived internal requirements. The main focus of this effort pertains to external requirements listed in a State of Idaho Governor's Settlement agreement with the Navy and DOE, which requires the shipment of 3,100 cubic meters of transuranic waste out of the State of Idaho by December 31,2002; shipment of which must begin not later than April 30, 1999. From these primary external requirements, interpretations were made based on functional requirements to ensure the transuranic waste will be shipped to the Waste Isolation Pilot Plant (WIPP) in accordance with these external requirements. Development (and documentation) of the interpretations of these requirements, as well as the assumptions being made were used in deriving the requirements. The evaluation only involves operational functions at this time.

It should be noted that program personnel, particularly in the TRU Waste program, are extremely knowledgeable about the requirements and their operational capabilities. Subject matter experts and the development of computer simulations, such as the Treatment Execution Model (TEM), are critical to the eventual success in meeting all requirements. The initial systems engineering effort largely focused on filling in the gaps of information for the derived internal requirements using these sources of information.

\section{Validation and Risk Management}

As the data is gathered and remaining gaps filled, the system now contains requirements that can potentially meet the external requirements. However, until the connection is made to the functions performing the work, nothing has changed. Before the requirements can be handed down to the functions, a validation step must be performed. Each function has a minimum of two constraints it must consider when evaluating if the internal requirements can be met. First, each function has a limit in budgeted dollars each year. Thus, major changes like adding operational staff is not generally something a functional manager can do to meet the potential requirements. Second, and related to the first, the function has certain capability due to facility, technology, personnel or other constraints and generally cannot consider substantially changing these conditions because of constraint number 1 . Thus, a functionally responsible manager must approve that the internal requirements can be met with consideration to the constraints for that function.

These functional evaluations that occur during the validation step allows program management to identify clearly where potential or real problems exist with meeting the external requirements. This is where risk management and mitigation can begin. Risk management can continue through the life of the program by evaluating performance against expectations as well as testing assumptions against the realities of performing the work. The initial information set that is planned to be validated is shown in template form in Figure 4. This validation effort will help to minimize program risk by identifying issues and conflicts early on, so that alternatives can be identified and corrective action taken. 


\begin{tabular}{l} 
Requirements Document (Each function \\
individually compiled) \\
Function Name: \\
WBS Element: \\
OBS Element Responsible: \\
$\quad$ Technical Budget Planned Funding \\
$\quad$ (Performance Meas.) \\
$97:$ \\
$98:$ \\
B9: \\
O0: \\
01: \\
O2: \\
EXTERNAL REQUIREMENTS \\
SUPPORTED BY THIS FUNCTION \\
(Inherited Requirements): \\
DEFINING REQUIREMENTS FOR \\
THIS FUNCTION: \\
ASSUMPTIONS FOR THIS \\
FUNCTION: \\
NNTERPRETATIONS: \\
\hline
\end{tabular}

Figure 4, Template of the Requirements Document Format

\section{Tracking Requirements and Change Control.}

As illustrated in Figure 5, the requirements, tasks and costs must be tracked and ultimately be placed under one change control process (Murphy et al, 1996). The requirements baseline, often called an Engineered Baseline, will include an accountability loop where the requirements agreed upon by the various program elements will be validated via a comparison of the work performed, the cost to perform it against the performance metric and agreed upon cost to meet the requirements. This process is still in design and will probably undergo design changes as it is negotiated with program management.

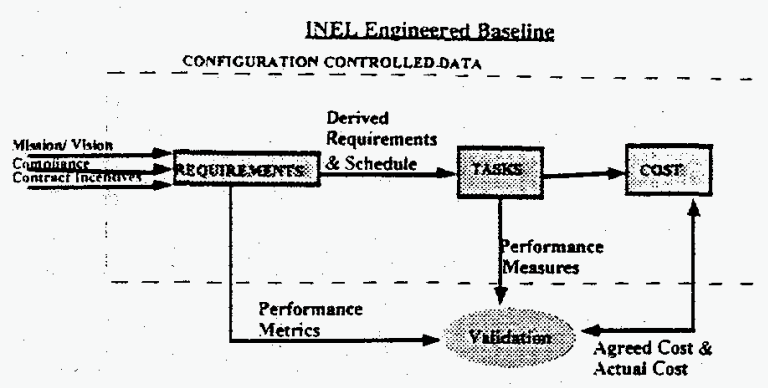

Figure 5, Engineered Baseline Elements

\section{Phase I Future Activities with Other Waste Streams}

A similar effort to that of the Transuranic Waste Program is required for Environmental Restoration and Mixed Low Level Waste and will be undertaken shortly. Following this, a review of the Nuclear Operations' requirements baseline (High Level Waste and Spent Nuclear Fuel) is necessary to ensure the content and scope is similar and consistent to these other waste streams. This will complete the Phase I effort.

\section{Phase II Planned Activities}

During Phase II, a further flowdown of the scoping requirements will be initiated for the infrastructure and supporting functions, which will identify the applicable derived requirements for these functions, e.g., training, infrastructure, etc. These infrastructure and supporting requirements are essential to meeting many, if not all, of the tactical or operational time-based requirements.

Ultimately, it is anticipated that nearly every function performed at the INEL that in some way supports the EM program can have the derived requirements identified. The responsible organization can be held accountable to the needed performance, and, through traceability, be informed nearly immediately upon a change in either requirements, interpretations, or assumptions that may affect the scope of work. These derived requirements will go through an approval cycle by the appropriate program management. The requirements, performance metrics, and agreed upon costs will be entered into a configuration controlled EM Integrated program requirements baseline. This will facilitate alternative identification, and the assessment and tracking of changes to mission objectives and stakeholder interests. Program performance will then be measured against the agreed 
upon metrics and costs. The process steps, as outlined in this paper, are summarized in Figure 6 (Plowman et al, 1996).

The long-term goal at the INEL from the systems engineering perspective is to allow DOE to change the budget through changing requirements, not just budget without a requirement change. This will offer two way accountability between DOE and the contracting management. Although the requirements development is going into its third year, progress continues. It is now obvious to systems engineering, that it will take a lot longer than first anticipated to create the consistent requirements driven organization discussed in this paper.

\section{REFERENCES}

Frandsen et al., "Integration of EM Activities at the INEL", Technical Report INEL95/0148, Lockheed Martin Idaho

Technologies Company, 1995.

Murphy et al., "Integration of the Idaho

National Engineering Laboratory

Environmental Management Activities

Using Systems Engineering", INCOSE

Paper, Lockheed Martin Idaho

Technologies Company, 1995.

Plowman et al, "Adapting Classical Systems Engineering to Department of Energy

(DOE) Needs", Technical Report INEL96/0262, Lockheed Martin Idaho Technologies Company, 1996.

State of Idaho Settlement Agreement with the U.S. Department of Energy on Spent Nuclear Fuel, signed October 6, 1995.

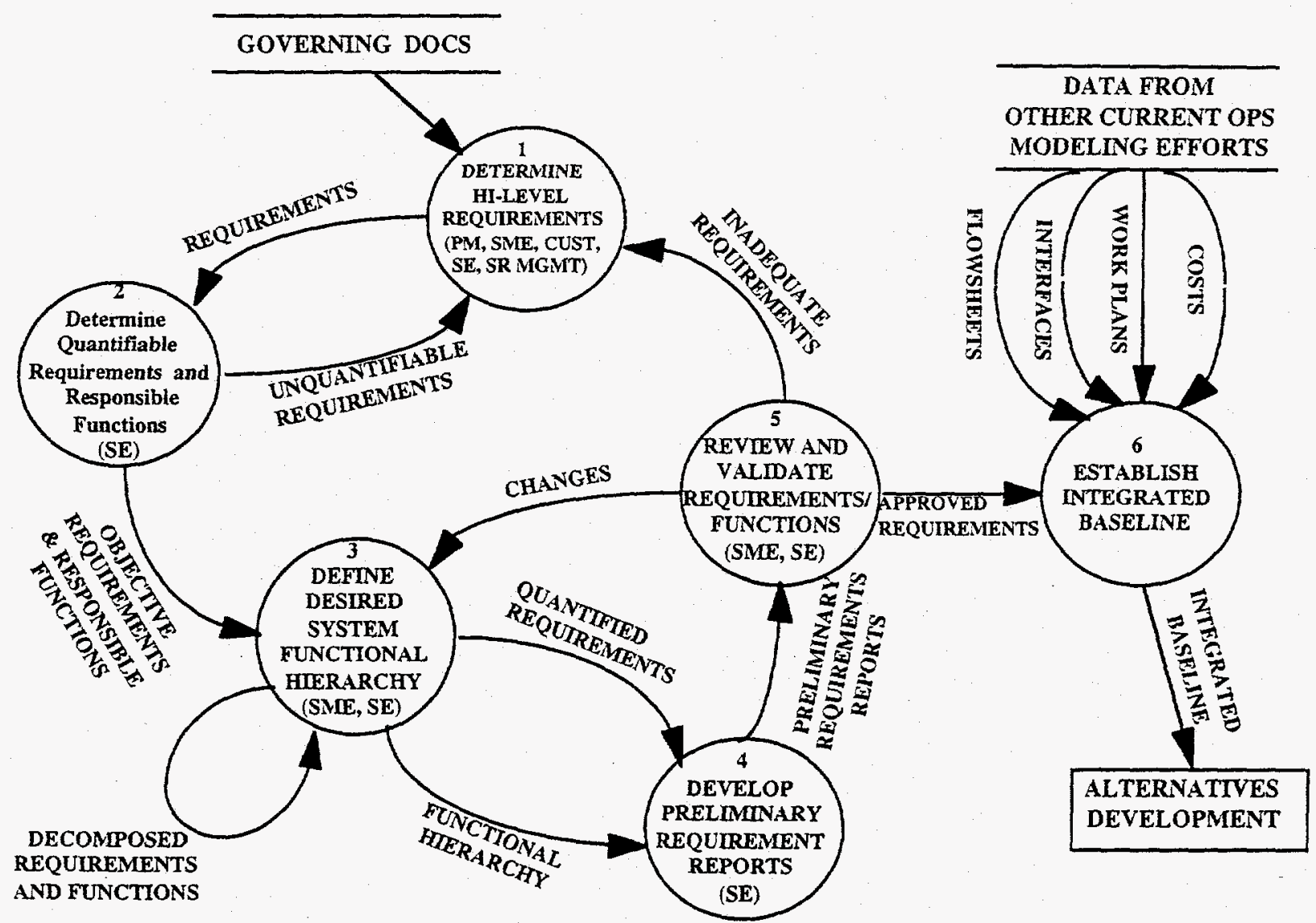

Figure 6, Process Flow Diagram for Requirements Baseline Development 


\section{BIOGRAPHIES}

James A. Murphy is a systems engineer from the Lockheed Martin Idaho Technologies Company (LMITCO) Systems Engineering Directorate and is matrixed to the EM Integration effort. His involvement with EM Integration has been from the initial phase of initiation through the current state of development and implementation. He has a BS from the College of Idaho in Chemistry and Biology with a MS from the University of Idaho in Chemistry. He has worked for the INEL for fifteen years with the last four years working on systems engineering and systems analysis.

Robert M. Caliva is a systems engineer from the LMITCO Systems Engineering Directorate and is matrixed to the EM Integration effort. He has a BS in General Engineering from the United States Military Academy, an MBA from the University of Central Florida and is presently pursuing an MS in Systems Engineering. He has been with the Lockheed Corporation for over 12 years in various engineering, systems analysis and management positions and came to the INEL in 1994. He joined the Systems Engineering Directorate and EM Integration in late 1996.

James R. Wixson is a systems engineer from the LMITCO Systems Engineering Directorate and is matrixed to the EM Integration effort. He graduated from the University of Utah in 1977 with a BS in Industrial Engineering and has an MBA from the University of Phoenix (1986). He is a Certified Value Specialist (CVS) through the Society of American Value Engineers (SAVE) and a Certified Manufacturing Engineer (CMfgE) through the Society of Manufacturing Engineers (SME). Jim has 20 years of experience and has been at the INEL for the past 7 years as an Industrial Engineer and Value Engineering facilitator under EG\&G and in Systems Engineering with LMTCO. 